\title{
Los obreros del petróleo y la nacionalización de la industria petrolera: Historia oral, historia oficial y sus límites*
}

\section{Alberto J. Olvera}

Il presente texto pretende analizar las representaciones hechas por los trabajadores petroleros de fines de los años 30 acerca de la etapa de la nacionalización petrolera (1938), contrastándolas con una investigación realizada en fuentes documentales. A su vez, el enfrentamiento nos conduce a cuestionar la historia oficial del periodo. Se observa de inmediato que este trabajo se inscribe en un intento para precisar los límites y los alcances del uso de la historia oral en investigación de la historia social de los trabajadores petroleros, al mismo tiempo que pretende establecer un cuestionamiento de la versión oficial de la propia historia obrera, en este caso la de los trabajadores del campo petrolero más importante de México a lo largo de tres décadas: Poza Rica.

La investigación básica en que se funda esta contribución se gestó desde 1983 en el Centro de Investigaciones Históricas de la Universidad Veracruzana. Su objetivo más importante fue, desde el origen, romper con una visión dominante de la historia de los obreros del petróleo como meros objetos de la voluntad del gobierno y de algunos prominentes líderes sindicales. Para ello se adoptó un enfoque que quiso ser thompsoniano, es decir, partir de un intento de historia social que entendiera a la clase obrera como un proceso y no como un agregado socioeconómico o una estructura predeterminada.

Además, la investigación se enfocó principalmente a un campo petrolero con el fin de rescatar las especificidades de la historia local y analizar con rigor las múltiples determinaciones de la formación de la cultura y la conciencia obreras en un periodo decisivo de la historia nacional.

Para lograrlo, la historia oral se convirtió en un método fundamental dada la carencia de fuentes documentales apropiadas. Así, se definió un programa de entrevistas que abarcó a casi tres decenas de sobrevivientes de la década de los años 30 , quienes participaron de una u otra manera, en la cuestión de la nacionalización. Apenas en 1986 se logró acceder al archivo de la Sección 30 del Sindicato de Trabajadores Petroleros de la República Mexicana, con sede en Poza Rica, gracias a lo cual pudieron consultarse las actas de las asambleas sindicales y los expedientes de las circulares que el Comité Ejecutivo Nacional del propio sindicato enviaba a todas las secciones desde su fundación en agosto de 1935. Esta información permitió establecer un contraste, debidamente fundamentado, entre los testimonios y las fuentes escritas.

\footnotetext{
* Ponencia presentada en el Primer Encuentro de Historiadores Orales de America Latina y España celebrado en el Instituto de Investigaciones Dr. José María Luis Mora, los días 23, 24 y 25 de septiembre de 1988.
} 
Es preciso decir desde este momento que el resultado más notable del contraste es la coincidencia de memorias y olvidos entre la historia oficial y la historia recordada por los viejos trabajadores, la cual se cuestiona fuertemente en los documentos a los que se ha tenido acceso.

Debe anotarse que varios factores contribuyen a que los trabajadores recuerden la historia vivida de manera fragmentaria y parcial. Primero, la preponderancia de lo nacional sobre los intereses puramente obreros en el caso de la industria petrolera en la época de la nacionalización. En efecto, no debe olvidarse que la lucha antiimperialista y nacional opacó el carácter de enfrentamiento obrero-patronal de la lucha establecida por los obreros de esta industria desde 1936, en búsqueda de un contrato colectivo nacional. Segundo, la realidad actual de la industria petrolera y de su sindicato, en completa contradicción con la herencia radical de las luchas del pasado, conduce a muchos a glorificar ese pasado. Tercero, los viejos trabajadores petroleros cargan sobre sus hombros una responsabilidad nacional, y no sólo gremial, en cuanto al mensaje de sus luchas de finales de los años 30 . En efecto, la trascendencia de la nacionalización petrolera en el conjunto de la historia contemporánea de México es tal, que la visión de los trabajadores sobre su participación en tal gesta se ve muy influida por los mitos y por la interpretación que la historia oficial le ha dado y con la cual no quiere romper.

Esta situación específica nos conduce a guardar una cierta distancia respecto al alcance de la historia oral como método de conocimiento objetivo por sí misma. Lo que nuestra experiencia indica es que el recuerdo de lo vivido es una combinación de una experiencia real, de una interpretación a la luz de la experiencia posterior y de la propia explicación oficial de los acontecimientos. Aparte, otro tipo de condiciones subjetivas conduce también a otras deformaciones de los hechos. Sin embargo, la utilidad de este método es extraordinaria para rescatar aspectos olvidados por las fuentes documentales; ante todo, los componentes básicos de la cultura obrera y la vida cotidiana. Sólo a través de la historia oral puede entenderse también el papel de las mujeres y la naturaleza de las luchas entre las corrientes político-sindicales dentro de cada sección, en cada época histórica, las cuales aparecen con frecuencia subsumidas en una generalidad sin contrastes.

Dicho esto, sólo nos resta agregar que el texto se compone de tres partes: la primera se refiere a los antecedentes necesarios para entender qué era Poza Rica y quiénes eran sus trabajadores; la segunda analiza las circunstancias específicas de marzo de 1938 y la forma en que se reorganizó la industria, así como la manera en que los trabajadores entendieron y vivieron esos drásticos cambios; la tercera se refiere a la suerte de la industria nacionalizada en sus primeros tres años de operación y la forma en que los obreros participaron, con sus luchas, en la fase de definición del carácter de la industria y de la correlación de fuerzas entre el Estado y los obreros del petróleo. Finalmente, se ofrece una breve conclusión que pretende resumir los alcances explicativos de la investigación.'

\footnotetext{
' Para una mayor profundidad en estos temas, sugerimos la lectura de "Origen
} 
$\mathrm{Al}$ arrancar los años 30 , la industria petrolera mexicana inició una lenta recuperación después de la profunda crisis que sufría desde mediados de la década de los 20 . Con ritmos desiguales y a través de una nueva distribución del poder relativo entre las distintas compañias extranjeras, la producción de crudo inició un modesto crecimiento a partir de 1932.

Este hecho, registrado en las estadísticas globales, ocultaba cambios profundos en el perfil de la industria. En efecto, las zonas productoras tradicionales (norte de la Huasteca veracruzana, la "Faja de Oro" y el extremo sur de Veracruz) continuaban su caída productiva, en tanto que surgían dos campos nuevos que explicaban el incremento de la producción nacional: Las Choapas (o el Plan) y Poza Rica, ambos pertenecientes a la Compañía Mexicana de Petróleo El Aguila, filial de la transnacional más poderosa de la época, la Royal Dutch Shell. ${ }^{2}$ A partir de 1934, esta compañía desplaza a las empresas norteamericanas del papel dominante que tenían al principiar la década y además va a permitirle reforzar su control sobre la refinación $\mathrm{y}$, por tanto, el abastecimiento interno de derivados y su exportación.

En este proceso la importancia de Poza Rica fue esencial. En 1934 se produjeron en este campo 590104 metros cúbicos de petróleo, o sea el $9.7 \%$ de la producción nacional, mientras que en 1936 se alcanzaban 2182231 metros cúbicos, o sea el $33.4 \%$ del total del país. Si a este último porcentaje agregamos lo que en la cercana Papantla (Campo Tajín) producia la Stanford Co., que eran 400 mil metros cúbicos, veremos que en esta nueva zona productora se aportaba cerca de la mitad de la producción nacional de petróleo. ${ }^{3}$

Por lo anterior el gobierno federal y la Compañía El Aguila pusieron especial interés en Poza Rica, que en 1937 fue considerado como el segundo campo más importante del mundo, sólo atrás de Richfield, Texas, y la única verdadera reserva de largo plazo en el pais, y que por cierto, vino a romper las muy pesimistas expectativas que las compañias extranjeras se habian formado de México a fines de los años 20 , cuando, a raíz del fracaso de muchas de sus exploraciones, pensaron que la industria no duraría muchos años más aquí. Cabe mencionar en este punto que nuestro país fue en 1921 el segundo productor más importante del mundo, gracias al auge de la "Faja de Oro" una estrecha franja de terreno en la cual se localizaron los mejores pozos petroleros del mundo de aquella época y cuyo éxito trajo a México enormes capitales provenientes de Estados Unidos, Inglaterra y Holanda.

El campo de Poza Rica se fundó en el año de 1932. ${ }^{4}$ En él confluyeron trabajadores cuyos orígenes sociales eran diversos: viejos obreros petroleros experimentados llegados de otros campos, trabajadores con experiencia industrial provenientes de otras ramas

social, condiciones de vida y organización sindical de los trabajadores petroleros de Poza Rica, 1932-1935", en Anuario IV del Centro de Investigaciones Históricas de la U. V. y "Los trabajadores ante la nacionalización petrolera: el caso de Poza Rica", en Anuario $V$, del CIH-UV, ambos del autor de estas lineas.

${ }^{2}$ Cf. Gobierno de México, El petróleo de México, México, 1940, cap. IV, p. 131142.

Ibid.

+ Cf. los artículos del autor citados en la introducción. 
productivas y trabajadores cuyo origen inmediato era el agro. Así, se mezclaron culturas obreras distintas en el contexto de un medio inhóspito y casi deshabitado, en un lugar incomunicado, en medio de una selva baja tropical cuyo único medio de contacto con el mundo era una vía de ferrocarril de $60 \mathrm{~km}$ que terminaba en el puerto de Tuxpan, el tercero más importante del estado de Veracruz.

Los trabajadores llegaron de diversas partes del país en búsqueda desesperada de empleo, justo en el año en que la crisis económica mundial golpeó más fuerte a México. Ahora bien, los trabajadores calificados y los de origen urbano vieron en un principio con marcado desprecio a los de extracción rural y crearon sus propios círculos amistosos e instituciones extrañas a los recién desempacados del campo, como las logias masónicas que habrian de tener una enorme importancia para el futuro político de Poza Rica.

Empero, la pequeñez del campo petrolero, el reducido número de los trabajadores (aproximadamente 1000 en el primer año) y la necesidad, derivada del proceso de trabajo, de integrar cuadrillas o equipos pequeños que convivian cotidianamente en el trabajo, permitió el establecimiento de relaciones entre los distintos tipos de obreros y cierto intercambio de experiencia. Por otra parte, las difíciles condiciones de vida y de trabajo, caracterizadas por el aislamiento, una aguda escasez de vivienda y el relativo despotismo de los patrones extranjeros, contribuyeron también al establecimiento de lazos solidarios entre los trabajadores.

En 1934 y a iniciativa de un grupo de trabajadores del departamento de bombeo de petróleo, se fundó en Poza Rica la delegación II de la sección I del Sindicato de Obreros y Empleados de la Compañia Mexicana de Petróleo El Aguila, con sede en la refinería de Ciudad Madero, Tamaulipas, en la cual se formó el primer sindicato petrolero con registro oficial y contrato colectivo de trabajo, en 1924, y que para esta fecha era considerado el sindicato petrolero más avanzado. Este logro, que costó varios sacrificios al grupo promotor, planteó a los trabajadores de Poza Rica una serie de acciones complejas, ante todo, la necesidad de reclasificaciones del personal y retabulaciones de salarios para poder aplicar el contrato de la sección I en Poza Rica. Al principio, y dada la inexperiencia de los dirigentes sindicales locales en materia laboral, fueron los líderes de la sección I los que asumieron esas tareas. Las reclasificaciones inauguraron una práctica que habría de convertirse en un factor fundamental de la participación obrera local, que fueron las asambleas departamentales, a través de las cuales prácticamente todos los trabajadores conocieron la existencia y el sentido de la organización sindical.

Los logros conseguidos por el sindicato, más el hecho de que la delegación asumió el monopolio de la contratación de trabajadores, incluso para las empresas que realizaban obras de construcción por contrato con El Aguila, acrecentó las filas del sindicato e interesó a un número cada vez mayor de trabajadores calificados. Poco a poco, el sindicato se convirtió en un verdadero factor del poder en Poza Rica y en un medio de homogeneización cultural de primer orden. Varios elementos determinaron este hecho:

a) Las prácticas sindicales democráticas que lo caracterizaron. 
No habia corriente en el interior de la delegación, se hacían asambleas cada semana y se respetaban las decisiones colectivas.

b) Se consiguieron importantes avances: otorgamiento de planta a cientos de trabajadores, reclasificación de muchos de ellos y aumentos salariales.

c) La asimilación de la tradición radical de lucha proveniente de Tampico, el centro petrolero nacional, y que era una herencia lejana de las corrientes anarcosindicalistas que fundaron los primeros sindicatos petroleros y cuyo discurso seguia siendo dominante en la sección 1 en los años 30 .

d) Rápida difusión de una cultura obrera proclive a la lucha económica y adaptada al patrón de vida de los campos. Pronto se aprendió lo que era un contrato colectivo y que la lógica del sindicato era obtener las mayores ventajas económicas posibles.

e) La agudización del conflicto nacional entre las empresas extranjeras y el gobierno federal y el sindicato petrolero nacional. En efecto, ya desde la Revolución se había planteado un enfrentamiento de las empresas petroleras contra el gobierno revolucionario, debido a la pretensión de éste de aplicar el artículo 27 constitucional y reclamar para la nación la soberania sobre los recursos del subsuelo, así como promover una reforma fiscal que gravara a las empresas. Las compañias extranjeras ganaron siempre y, de una u otra manera, lograron obligar al gobierno a respetar su poder y sus prerrogativas. Pero con la llegada de Lázaro Cárdenas a la presidencia a fines de 1934 , el asunto volvió a agudizarse y tuvo un nuevo repunte desde fines de 1936 debido a la pretensión del recién fundado Sindicato de Trabajadores Petroleros de la República Mexicana (STPRM) de establecer un contrato colectivo nacional. El sindicalismo en Poza Rica surge precisamente en estas circunstancias.

A principios de 1937 , la delegación II se convirtió en la sección 30 del STPRM y sus dirigentes entran de lleno a la lucha obrero-patronal planteada por el sindicato contra el conjunto de las empresas petroleras extranjeras. En noviembre de 1936, ante la presión sindical y con la intervención gubernamental, el sector patronal consintió en establecer una convención entre obreros y patrones para redactar un contrato-ley aplicable a toda la industria. Esta fase, que va a durar hasta mayo de 1937 , se caracteriza por la centralización del conflicto en los dirigentes nacionales y seccionales del sindicato. Los dirigentes locales aprenden los secretos de la alta politica, se codean con los lideres de la Confederación de Trabajadores de México (CTM) y adquieren una visión global de la industria. Transmiten este aprendizaje a sus compañeros por diversos medios: informes semanales a sus secciones, circulares del Comité Ejecutivo General enviadas casi a diario, presencia de los comisionados en las asambleas seccionales. Así, en Poza Rica en los años de 1936 y 1937 se celebraron 70 asambleas seccionales por año, de las cuales 52 fueron ordinarias y 18 extraordinarias. Tan intensa actividad sindical permitió la socialización de una cultura sindical y politica común entre los trabajadores de este campo.

${ }^{5}$ Archivo de la Sección 30 del STPRM (A.S. 30), expediente 003-2 (Libros de actas), antos 1936-1937. 
Ante el fracaso de la convención obrero-patronal, el STPRM realizó una huelga de 9 días a fines de mayo y principios de junio de 1937. La huelga fue levantada cuando la dirigencia sindical aceptó entablar un litigio de orden económico contra las empresas. Este método legal depositaba en la Junta Central de Conciliación y Arbitraje, es decir, en el gobierno, la decisión de si las demandas sindicales eran correctas o no, según la evaluación que del estado financiero de las empresas hiciera una comisión de peritos nombrada ex profeso por la propia Junta. Poderosas razones de Estado, entre ellas la terrible escasez de energéticos generada por la huelga, y la intención del gobierno de conocer a fondo la contabilidad de las empresas, habían impuesto esta táctica.

La situación tomó a la sección 30 a medio camino de su negociación particular con El Aguila para adecuar el contrato colectivo de la sección 1 a las condiciones del campo, puesto que, al constituirse en sección en enero de 1937, la 30 tuvo necesidad de firmar un contrato específico con la empresa. El Aguila aprovechó el impasse creado por el problema de orden económico para no resolver el problema de Poza Rica, argumentando que lo más pertinente era esperar el resultado de la demanda del STPRM. Ante la cerrazón de la compañia, que era una táctica deliberada en el contexto del conflicto empresas-gobierno, los trabajadores de Poza Rica decidieron estallar una huelga a fines de julio de $1937,{ }^{6}$ a pesar de tener en contra la voluntad del gobierno y la de la propia dirigencia nacional del sindicato.

Con un pliego petitorio que contenía 76 puntos, los obreros de Poza Rica realizaron un movimiento que habria de durar 57 dias y que traeria como consecuencia una nueva escasez de gasolina y otros derivados en todo el país, pues para ese año, el campo producía ya el $40 \%$ del crudo nacional.

Este movimiento constituye el primer reflejo de la diferencia entre la historia registrada por los protagonistas, que es en cierta forma reproducida por la historia oficial (véase el folleto de PEMEX llamado Poza Rica: apuntes para su historia) y la historia consignada documentalmente. Los trabajadores recuerdan esta huelga como un momento cumbre del heroísmo obrero y como la coyuntura que permitió la identificación total entre los propios trabajadores y entre éstos y el resto de la población. Por ejemplo:

La huelga de 57 días fue un acto valiente y maravilloso. Todos los trabajadores jalamos parejo y resistimos a pesar de no tener un fondo de resistencia apropiado. Los tenderos nos fiaron, en las cantinas también y hasta las muchachas en los cabarets nos abrieron crédito. De esa época tengo recuerdos del apoyo de nuestras familias frente a El Aguila. Al final ganamos la mayoria de nuestras demandas y contamos siempre con el apoyo del gobierno.?

Y efectivamente, de acuerdo con los testimonios, la huelga significó un momento de unidad interna del gremio petrolero que resultó muy importante para los años siguientes, así como la

${ }^{6}$ A. S. 30, exp. 013-2 (Circulares del Comité Ejecutivo General), Circulares de julio de 1937. 1984. 
primera ocasión en que el pueblo de Poza Rica se incorporó a la lucha de los petroleros.

Sin embargo, analizando la hemerografía y el Archivo General de la Nación, se encuentra uno con que después de 20 días de huelga, el gobierno modificó su posición, y de apoyar plenamente a los trabajadores pasó a exigirles moderación. En septiembre de 1937, cuando la huelga empezó a hacer estragos en el país a causa de la escasez de derivados, el propio presidente Cárdenas lanzó claros exhortos a levantar la huelga. A los 50 dias de huelga, apenas 20 de las 76 cláusulas del pliego petitorio habian sido resueltas. Seis dias después, el presidente lanzó un ultimátum público a los trabajadores de Poza Rica, a quienes llama parciales y localistas, pues hacen prevalecer sus intereses particulares por encima de los de la nación. Acusa de un radicalismo exagerado a sus líderes y los llama a deponer su actitud. ${ }^{8}$ Los obreros de Poza Rica deben aceptar la promesa de que las negociaciones continuarán con la intervención del Departamento Autónomo del Trabajo.

En la práctica, el radicalismo de los obreros pozarricenses no disminuyó. Junto con la negociación que se realizaba en México, la sección 30 realiza continuos paros de labores para presionar a la empresa a ceder, lo cual escandaliza al propio gobierno y a El Aguila, que para aquellos momentos estaban pactando un acuerdo inusitado, cuya importancia estaba por encima de cualquier interés obrero particular. En efecto, en noviembre de 1937 El Aguila y el gobierno federal van a firmar un convenio sin precedentes mediante el cual se otorga a la compañia una nueva concesión de 50 años para explotar el campo a cambio de que otorgue el $35 \%$ de la producción obtenida a la empresa petrolera estatal Agencia General del Petróleo Nacional (AGPN). Este trato pretendía romper el frente empresarial y garantizar al gobierno un mayor control de la producción.

En este esquema, el radicalismo de los obreros de Poza Rica constituía un obstáculo. Por ello el gobierno ordenó el exilio de Poza Rica de Eduardo Pérez Castañeda negociador principal de la sección 30 y amenazó a los demás dirigentes naturales de la sección, haciéndolos responsables de los paros ilegales. La realidad era que la base obrera tomaba las decisiones de los paros en asambleas y, a veces, en contra de las recomendaciones de sus dirigentes. Sin embargo, el gobierno pensaba que los obreros no podían actuar ni pensar por si mismos.

El periodo de inestabilidad se extiende hasta el año de 1938. Cabe anotar que gracias a su presión los obreros de Poza Rica consiguieron la base para más de 500 trabajadores y la firma de un nuevo contrato. Sin embargo, esta etapa decisiva de la historia local en el cual las relaciones entre obreros y gobierno se deterioraron, ha sido "olvidada" por los trabajadores.

Como es sabido, el 18 de marzo de 1938 se decretó la expropiación de las compañias petroleras extranjeras y se puso en marcha un operativo ya acordado desde febrero entre el gobierno y el STPRM, según el cual habrían de constituirse en cada sección consejos locales administrativos, formados por el secretario general seccional, el secretario del trabajo y el presidente del consejo local de

${ }^{8}$ El Nacional, 13 y 14 de septiembre de 1938. 
vigilancia para dar continuidad a la producción. ${ }^{9}$ En el nivel central se nombró un consejo de administración del petróleo integrado por cinco representantes del gobierno y cuatro del STPRM, quien se encargaria de la gestión central de la industria.

La constitución de los consejos locales administrativos significaba que el sindicato, en la figura de sus dirigentes locales, pasaba a ocupar la dirección de la producción de petróleo crudo y refinado, no asi del aparato administrativo central. Así, en la asamblea sindical se tomaron determinaciones sobre a quiénes dar o quitar el trabajo o cómo realizar algunas labores, por lo menos en Poza Rica. Además, hubo un espacio para la iniciativa de los trabajadores calificados, quienes de hecho pasaron a asumir la dirección operativa de la empresa. La posibilidad del control obrero en el proceso productivo en los campos petroleros está fundada en la naturaleza misma de los procesos de trabajo que constituyen la industria a este nivel, y en todos los cuales predomina el saber artesanal y la experiencia por encima de la calificación técnica: reparación y mantenimiento de maquinaria, vigilancia y control de procesos de flujo continuo, perforación de pozos, creación de infraestructura y el trabajo administrativo.

Estos procesos eran conocidos y controlados por los trabajadores de acuerdo con su experiencia y su habilidad artesanal, incluida la perforación, si bien en este terreno el conocimiento estaba menos difundido debido a la política de las compañias extranjeras, que impedian que hubiera perforadores mexicanos. Así, los trabajadores calificados podían controlar el proceso productivo en su conjunto sin necesidad de técnicos, excepto en la exploración y en la gestión científica de la perforación.

En cambio, en la actividad administrativa central se carecía en su totalidad de experiencia. Esto propició en la administración central un verdadero "vacío de dirección" en el momento posterior a la nacionalización, cosa que no se dio en la producción inmediata en la que, en todo caso, sólo se presentó como problema grave la escasez de refacciones y equipos, lo cual pudo solucionarse, hasta cierto punto, gracias al concurso de los trabajadores calificados.

De estos primeros momentos de la nacionalización, tanto la historia oficial como la memoria colectiva son sumamente parcas. En efecto, más allá de excelsos reconocimientos al sacrificio de los obreros, no se encuentran en la historia escrita referencias concretas a la actividad obrera. La hipótesis general es que sin el concurso de los trabajadores la industria no hubiera salido a flote, pero si bien esto es absolutamente cierto, es necesario anotar que ante la falta de estudios precisos o de explicitación de las condiciones concretas el público no entiende lo que realmente pasó, quedando la imagen de que los trabajadores se limitaron a trabajar duro y que los nuevos dirigentes empresariales funcionaron con eficacia. Los propios trabajadores producen una imagen similar para el consumo de las nuevas generaciones y sólo cuando me-

\footnotetext{
A. S. 30, exp. 041-2, Informe del C. E. G. del STPRM de su gestión en el periodo $1938-39$.

10 Véase, del autor: "Los trabajadores ante la nacionalización petrolera", en Anuario $V$, CIH-UV, Xalapa, 1988.
} 
diante una entrevista dirigida se profundiza en el tema, salen a relucir los detalles íntimos del proceso.

Por lo que se refiere al papel de los trabajadores, valga señalar lo siguiente:

Después de la nacionalización las compañías extranjeras impusieron un boicot a la industria. No habia refacciones ni se podían conseguir barrenas para seguir perforando. Por ahí el gobierno consiguió comprar en el mercado negro diamantes de perforación. Yo, como soldador, tenia que ponerlos en las barrenas que fuimos a recoger a los tiraderos de chatarra. Ensayé varias formas de colocarlos y luego anduve preguntándole a los perforadores qué tan buenas les habian salido mis barrenas. Así como yo inventé una forma de reutilizar las barrenas, los companeros de pailería y del torno hicieron maravillas para fabricar las piezas que se descomponían en las máquinas y a veces para reponer partes completas de motores o de mecanismos que se utilizan en la industria. De no ser por esta voluntad nuestra de usar nuestros conocimientos para sacar adelante la industria, yo no sé qué hubiera pasado. Los ingenieros se fueron todos. Los nuevos ingenieros jóvenes que mandó el gobierno no sabian absolutamente nada. La verdad es que en los primeros tres o cuatro años en la industria se hizo lo que opinaban los trabajadores calificados."

Estos hechos no cuentan para las nuevas generaciones, han sido subsumidos en el conjunto de una historia heroica que coloca en primer término al presidente Lázaro Cárdenas como el gran gestor de la nacionalización petrolera y remite a un lejano y abstracto segundo lugar el papel de los trabajadores sin rostro y sin nombre que fueron quienes en realidad permitieron superar la crisis.

Existe otro nivel de la realidad inicial de la nacionalización que permanece en el olvido. Nos referimos a los conflictos internos entre los dirigentes sindicales y los pleitos entre éstos y el gobierno. En efecto, la situación creada después de la nacionalización otorgó un enorme poder a los trabajadores en general pero muy especialmente a los líderes sindicales. La imagen dominante era la siguiente:

La administración centralizada de la industria petrolera ahorrará millones de pesos, que representan los fabulosos sueldos y privilegios de los gerentes, de los altos jefes, de los técnicos nominales de la industria y la muchedumbre de abogados. ${ }^{12}$

En realidad, la lógica elemental indicaba que, en efecto, la nacionalización evitaría las múltiples duplicidades administrativas en que incurrían las empresas extranjeras por su alto número y que se eliminarian una gran cantidad de puestos administrativos ahora innecesarios. Esta seguridad es lo que permitió al gobierno asegurar que muy pronto los trabajadores petroleros se verian beneficiados con la aplicación del famoso laudo del 18 de diciembre de 1937, el cual no fue aceptado por las compañías extranjeras, motivo por el cual sobrevino la expropiación. 1983.

1 Entrevista A. Olvera-Heriberto Martinez, Poza Rica, Ver., 12 de mayo de

Palabras de Vicente Lombardo Toledano el 19 de marzo de 1938, citado en: Julio Valdivieso, Historia del movimiento sindical petrolero en Minatitlán, edición del autor, México, 1963, p. 112. 
Sin embargo, los intereses materiales concretos de los propios dirigentes sindicales y el carácter local de la cultura obrera petrolera determinaron la existencia de dificultades insuperables para materializar la centralización. Las secciones del sindicato petrolero se habían conformado según el lugar de trabajo y la empresa para la cual los trabajadores prestaban sus servicios. Así, había cuatro secciones con sede en la ciudad de México debido a que ahí cada una de las grandes empresas tenía oficinas administrativas y había seis secciones en Tampico por la existencia de varias refinerías y plantas de embarque de las diversas empresas. Dado que los consejos locales administrativos se integraron con los principales dirigentes sindicales, esta organización reprodujo la duplicidad de la etapa anterior. Ahora bien, dado que los trabajadores sentían que podian tener algún control sobre sus dirigentes seccionales, mas no sobre los líderes de otras secciones o los nacionales, optaron por luchar por que sus dirigentes seccionales conservaran los puestos administrativos recién adquiridos. Además, los propios líderes empezaron a ser usufructuarios de un enorme privilegio social: empezaron a devengar salarios mucho más altos que en el pasado y a detentar un poder extraordinario.

En julio de 1938 el presidente Cárdenas emitió un decreto según el cual se declararon extinguidos los consejos locales administrativos, creándose oficialmente la empresa Petróleos Mexicanos, bajo el control del gobierno federal y con una participación minoritaria de los trabajadores en su consejo de administración, el cual nombraria a los superintendentes de los campos y refinerías. ${ }^{13} \mathrm{El}$ decreto tampoco acabó con la dispersión y duplicidad administrativa. Con el objeto de mantener la calma dentro de las filas sindicales, fueron nombrados superintendentes los principales líderes sindicales de cada sección, aunque ahora pasaron a convertirse en personal de confianza es decir, bajo el control del gobierno y no del sindicato. Surge a partir de este momento una dualidad de funciones en los líderes sindicales: por un lado son representantes de los trabajadores y por otro son los representantes de la empresa. Esta dualidad condujo a múltiples confusiones y a innumerables conflictos entre el gobierno y el sindicato petrolero. El gobierno exigía que los líderes fueran fieles a los intereses de la empresa nacionalizada y los trabajadores exigian que lo fueran a los intereses de la base. A su vez, los líderes tenían sus propios intereses personales.

En esta etapa, que duró por lo menos hasta 1940 , los enfrentamientos por el poder entre las diversas secciones del sindicato petrolero, entre las diversas facciones de cada sección y aun entre los distintos departamentos de un mismo campo o refinería son la regla cotidiana. Sin embargo, estos hechos no constan en la historia oficial, ni tampoco ocupan un papel relevante en la memoria colectiva. Los líderes sindicales a los que les tocó vivir esta fase tan conflictiva, han borrado de su memoria los detalles que dan vida y materialidad a los conflictos. La historia oral posterior a la nacionalización resulta más bien plana y alude solamente a los más importantes enfrentamientos entre la empresa y el sindicato.

${ }^{13}$ Decreto oficial citado en Juan Garcia Hernández, El cuchillito de palo, edición del autor, México, 1967. 
Por ejemplo: "Después de la nacionalización hubo muchos problemas en la industria debido a que hubo varias luchas por el poder, pero eso no es importante, ya que lo importante fue que en la sección 30 la asamblea aprobó por unanimidad la expropiación y tal era nuestra emoción que, cuando ya estaba todo terminado, se paró un pelao, un borrachales al que le deciamos el timbiriche y dijo que se agregara al acuerdo un mensaje al general Cárdenas para decirle que si no había dinero para que se les pagara a los trabajadores, éstos de todas formas iban a trabajar por amor a México. Son detalles que salen del corazón. Así que los pleitos que hubo después fueron en realidad secundarios. Y es que es de comprenderse que las cosas estuvieran difíciles. Durante varios meses nos pagaron el mismo sueldo que teníamos desde 1937 y a fines de marzo del 38 sacaron a varios eventuales. Pero luego la cosa cambió y empezaron a entrar más trabajadores, incluso más de los que hacian falta, por razones muy humanas, muy comprensibles; uno llegaba y les decía a los líderes: óyeme, hazme el favor de meter a chambear a mi hermano, a mi hijo, a mi compadre que se está muriendo de hambre. Y los demás lo aceptaban, se entendía el caso. Claro está que a la larga esto tenía que causar problemas con el gobierno." 14

Los enfrentamientos fueron mucho más allá de un pleito secundario. Fue una verdadera lucha por el poder en la que se confrontaron intereses y posturas ideológicas. Los dirigentes que entraron en funciones a partir de 1939 entendieron que la dicotomía era peligrosa y que lo mejor que podian hacer era solicitar la administración obrera en toda la industria, es decir, una forma legal según la cual el sindicato se encargaría de la administración global de toda la industria y el gobierno sólo de su supervisión. El antecedente inmediato era el caso de los Ferrocarriles Nacionales de México. ${ }^{15}$ Sin embargo, el gobierno nunca aceptó esta propuesta, porque, como dijera el licenciado Leñero, secretario particular de Cárdenas en el inicio de la Convención Extraordinaria del STPRM de 1939: "El gobierno no puede dejar de lado su responsabilidad de administrar directamente una industria estratégica, además de que debe garantizarle a las empresas extranjeras el pago de sus indemnizaciones."16 En la práctica, el poder sindical no pudo ser anulado de la industria sino hasta fines de 1940, cuando mediante un laudo de la Junta de Conciliación y Arbitraje, originado en una demanda de carácter económico que dirigió PEMEX contra STPRM, se despidió a todo el personal que había ingresado a la industria después de marzo de 1938 y se redujo el número de puestos administrativos así como sus salarios. Más allá de estas acciones administrativas, lo que en el fondo de este conflicto estuvo fue la exclusión de los trabajadores de la dirección de la empresa.

\footnotetext{
It Entrevista A. Olvera-Rafael Suárez Ruiz, Poza Rica, Ver., 14 de abril de 1984.

15 Véase Ruth Adler, "La experiencia de la administración obrera en PEMEX: Un ensayo interpretativo", en Anuario $V$, op. cit.

${ }^{16}$ Cf. Fabio Barbosa Cano, "El movimiento petrolero en 1938-1940", en J. Aguilar (coordinador), Los sindicatos nacionales: Petroleros, México, G. V. editores, 1986, p. 64 .
} 
Cabe aclarar, sin embargo, que este proceso no se expresó de la misma manera en todas las secciones. En Poza Rica la tradición de lucha radical y la democracia sindical efectiva significaron un dique a las pretensiones hegemónicas del superintendente local, Eduardo Pérez Castañeda. En Poza Rica fueron muy pocos los lideres sindicales que pasaron a la administración, y ello les permitió mantener una actitud de crítica constante y no confundir su papel con el de la administración. Pérez pretendió crear su propio grupo sindical y acabar con la influencia de los grupos radicales, pero no lo pudo lograr. Y esto fue así porque los superintendentes sabian que para mantener su puesto requerian el apoyo de la base trabajadora. Pérez pasó de ganar $\$ 535$ mensuales como secretario del superintendente extranjero, a percibir $\$ 1500$ mensuales como superintendente formal, a más de disponer de un poder extraordinario. No era poco entonces lo que se podía perder. La lucha contra este intento hegemónico culmina a principios de 1940 cuando Pérez acusa al secretario seccional David Cano de intentar sabotear la producción como parte de un plan de los comunistas. El gobierno investigó el caso y llegó a la conclusión de que las acusaciones eran falsas por lo que, para evitar mayores daños, sacó a Pérez de Poza Rica.

El poder obrero en Poza Rica se expresó también en el rechazo a los planes del gobierno de llevar a cabo en 1939 la perforación de pozos por contrato con la empresa extranjera Davis and Co. La sección 30 demostró, con números en la mano, que ese proyecto era completamente inaceptable en términos económicos, políticos y técnicos. ${ }^{17}$ La sección 30 consideró que el acto ilustraba una idea del gobierno de desconfianza hacia la capacidad de los perforadores mexicanos. Conflictos como éste llevaron a los trabajadores a solicitar la destitución del ingeniero Vicente Cortés Herrera, gerente general de PEMEX, por incapacidad.

Nada de esto registra, como es lógico, la historia oficial. Los libros editados recientemente por PEMEX por el 50 aniversario de la nacionalización, hacen caso omiso de estos procesos internos que fueron definitivos para el curso futuro de la industria. Pero la memoria de los trabajadores tampoco ha retenido estos hechos ni otros más que afectaron su vida cotidiana: las malas condiciones de vida, la continuidad de la carencia de vivienda y de servicios en Poza Rica, por ejemplo; la continuidad, en suma, de las condiciones y circunstancias en que se reproducía la vida social en los campos y refinerías.

En efecto, es notable apreciar que los trabajadores que no asumieron un papel protagónico en los procesos político-sindicales de la época no refieren con precisión la naturaleza de las condiciones en que se desenvolvía la vida cotidiana en los primeros años de la nacionalización. Antes que nada permanece el recuerdo de que la ausencia de los jefes extranjeros modificó el ambiente político local y que se abrieron grandes expectativas que ellos consideran materializadas en el hecho de que sus hijos pudieron estudiar, el país se desarrolló y ellos conservaron el empleo y mejoraron sus condiciones de existencia en el largo plazo. Esta certidumbre lleva - a confundir los tiempos y a entender la época de la nacionaliza-

17 Véase Olvera, "Los trabajadores ante...", op. cit. 
ción petrolera como una sola etapa histórica que aún sigue vigente:

con la nacionalización mejoramos bastante. Se fueron los jefes gringos y nos quedamos nosotros. Poco a poco se fue viendo que los niños tuvieran las escuelas necesarias y se fue resolviendo lo de la atención médica. En Poza Rica produjimos cada vez más petróleo y se contrataron cada vez más trabajadores. Se pudo dar empleo a nuestros hijos y muchos pudieron llegar hasta la universidad. ${ }^{18}$

Las mujeres guardan una imagen similar, si bien son mucho más perceptivas de los rasgos de la vida cotidiana. Por ello mismo sitúan mejor la continuidad de los hechos más allá de las convulsiones políticas. Sin embargo, reconocen, en algunos casos, su participación en la vida política local a raíz de la nacionalización: "La celebración de las fiestas patrias, del 18 de marzo y otras ocasiones era de todo el pueblo, no como las asambleas sindicales, donde nomás iban los puros hombres más políticos."19 De ahí en fuera, la vida cotidiana de las mujeres no varió en absoluto, como tampoco lo hizo la llamada "cultura del petróleo", es decir, la cultura popular tradicional en los campamentos petroleros.

A pesar de la enorme participación obrera en la vida sindical, los secretos y el sentido de la alta política sólo fueron entendidos cabalmente por la elite dirigente. Sin embargo, el recuerdo de las asambleas multitudinarias, las decisiones por voto universal y los múltiples actos de lucha aún perviven en los viejos trabajadores. Pero casi 40 años de antidemocracia posterior han hecho añicos la viveza y el recuerdo de esos sentimientos.

En este texto nos hemos movido en el nivel de la historia políticosindical en Poza Rica a fines de los años $30 \mathrm{y}$ hemos analizado superficialmente, por medio de la historia oral, la forma en que los trabajadores de la época recuerdan su participación en los acontecimientos de la época y el significado de éstos en sus vidas.

Sin tener el espacio para demostrar suficientemente, se puede decir que lo que resalta, es que en el nivel de la vida político-sindical de la época de la nacionalización petrolera, en la memoria colectiva el cambio juridicopolítico que significó la nacionalización, y sus efectos benignos a largo plazo en el medio petrolero determinaron una percepción acrítica de los hechos y condujeron a avalar el gran mito construido posteriormente. De alguna manera, los trabajadores consideran que su propio papel se veria cuestionado en una interpretación crítica de sus enfrentamientos con un gobierno al cual guardaron (y guardan aún) un profundo reconocimiento y un extraordinario respeto. No puede olvidarse que esos años son los años de Lázaro Cárdenas, cuya figura está por encima de los conflictos. Es por eso que este "olvido" es explicable, pero nos indica también que ciertos prejuicios colectivos pueden cortar la percepción objetiva de los procesos históricos.

Lo que se recuerda es lo que afirma el sentido histórico de la acción de los trabajadores, su utilidad para la nación. El sentido

\footnotetext{
18 Entrevista A. Olvera-Herminio Govea, Poza Rica, Ver., 15 de enero de 1985.

19 Entrevista A. Olvera-Maria Rosa Oliva de Tapia, Poza Rica, Ver., 16 de abril
} de 1987. 
critico se reserva siempre para el presente o para tiempos relativamente cercanos. Por otra parte, el "olvido" es básicamente, para la mayoria de los que eran trabajadores de base en la época analizada, falta de comprensión cabal de lo que estaba sucediendo. Para los lideres que sobreviven, el "olvido" es una forma, muchas veces consciente, de evitar la ruptura de los mitos dominantes y evidenciar su propio papel en los conflictos, es decir, de ocultar sus propios intereses concretos políticos y materiales.

La historia oral aparece así, en los momentos de quiebre histórico, acotada por las percepciones, los prejuicios y los mitos tanto del pasado como del presente. Pero en un balance global, debe decirse que mediante la contrastación de las representaciones se llega a la comprensión de lo que la historia de la nacionalización representa, tanto para los que la vivieron como para las nuevas generaciones, a más de arrojar luz sobre hechos ocultos y olvidados acerca de la verdadera participación obrera en dicha gesta.

En este sentido, la recuperación oral de las representaciones colectivas define también el campo en que debe darse la lucha ideológica y cultural para conformar una revaloración del pasado a la luz de los cambios que exige el presente. 